\section{Arterial duct angioplasty as an adjunct to dilatation of the valve for critical pulmonary stenosis}

\author{
Kevin P Walsh, Simon E Abrams, Robert Arnold
}

\author{
Heart Clinic, Royal \\ Liverpool Children's \\ Hospital, Alder Hey, \\ Liverpool \\ K P Walsh \\ S E Abrams \\ $R$ Arnold \\ Correspondence to: \\ Dr K P Walsh, \\ Heart Clinic, Royal \\ Liverpool Children's \\ Hospital, Alder Hey, Eaton \\ Hospital, Alder Hey, Eaton
Road, Liverpool L12 2AP. \\ Accepted for publication \\ 21 September 1992
}

\begin{abstract}
Objective-To assess the efficacy of arterial duct angioplasty in maintaining adequate ductal patency in neonates with critical pulmonary valve stenosis.
\end{abstract}

Patients-Two neonates presenting with cyanosis due to critical pulmonary valve stenosis with severe right ventricular hypoplasia underwent percutaneous balloon dilatation of the pulmonary valve. Despite successful dilatation, both remained cyanosed while receiving prostaglandin $E_{2}$ infusions.

Results-Angioplasty of the arterial duct resulted in increased arterial oxygen saturations. Adequate arterial duct patency was maintained for three months during which time right ventricular dimensions increased enough to allow sufficient pulmonary circulation without the duct.

Conclusions-Arterial duct angioplasty is an effective additional treatment for patients with critical pulmonary valve stenosis whose right ventricle is too small to provide adequate forward flow after balloon dilatation of the valve. Arterial duct angioplasty sustains adequate patency of the duct while the right ventricle grows sufficiently to undertake the pulmonary circulation.

(Br Heart f 1993;69:260-262)

Neonates with critical pulmonary valve stenosis and an intact ventricular septum present soon after birth with cyanosis due to inadequate pulmonary blood flow. ${ }^{1}$ Current management consists of balloon dilatation of the critically stenosed pulmonary valve. ${ }^{2-4}$ Although many of these patients have significant associated right ventricular hypoplasia, these hypoplastic ventricles can grow if continuity between the right ventricular cavity and pulmonary artery is established. ${ }^{5}$ Patients whose right ventricle is too small alone to provide adequate pulmonary blood flow after a technically adequate dilatation of the pulmonary valve, require a systemic to pulmonary shunt or prolonged administration of prostaglandin (PG) $\mathrm{E}_{1}$ or $\mathrm{E}_{2}{ }^{4}$ Unfortunately, $\mathrm{PGE}_{2}$ infusions produce sustained clinical improvement in only $60 \%$ to $88 \%$ of patients with cyanotic heart disease. ${ }^{6}$

We have recently shown that angioplasty of the arterial duct restores the systemic circulation of neonates with severe left heart obstruction who are unresponsive to infusion of $\mathrm{PGE}_{2} \cdot{ }^{7}$ We now report the use of angioplasty of the arterial duct in two neonates with critical pulmonary stenosis and severe right ventricular hypoplasia who remained cyanosed after balloon dilatation of the pulmonary valve despite prostaglandin infusion.

\section{Patients and methods}

Two neonates (aged five and four days; weight 4.0 and $3.9 \mathrm{~kg}$ ) presented with cyanosis. A PGE $\mathrm{PG}_{2}$ infusion had been started at their referring hospital. A continuous murmur at the left infraclavicular area was easily heard in both patients. Chest $x$ ray film showed normal heart size and pulmonary oligaemia Electrocardiograms showed sinus rhythm with right atrial enlargement, and a QRS axis of $+70^{\circ}$ with upright $\mathrm{T}$ waves in $\mathrm{V} 3 \mathrm{R}$ and $\mathrm{V} 1$ Cross sectional echocardiography showed critical pulmonary valve stenosis with a peak Doppler jet of 4.7 and $4.5 \mathrm{~m} / \mathrm{s}$. There was severe right ventricular hypoplasia in both patients. The arterial duct was the main source of pulmonary blood flow with a continuous aorta to pulmonary artery Dopple profile. Colour flow mapping showed predominantly right to left shunting across the foramen ovale.

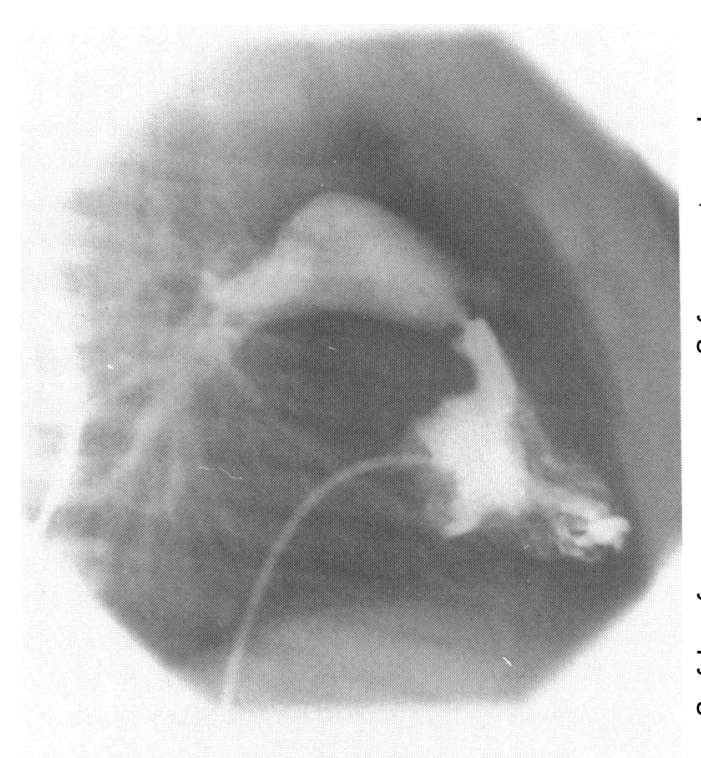

Figure 1 Right ventriculogram (patient 1, left lateral projection) performed before dilatation of the valve showing a tiny jet of contrast through the critically stenosed pulmonary valve and the associated severe right ventricular hypoplasia. 
Figure 2. Angiogram of the arterial duct after angioplasty (patient 2, left lateral projection). $A$ widely patent and slightly irregular arterial duct fills the main pulmonary artery and contrast can be seen regurgitating into the hypoplastic right ventricle.

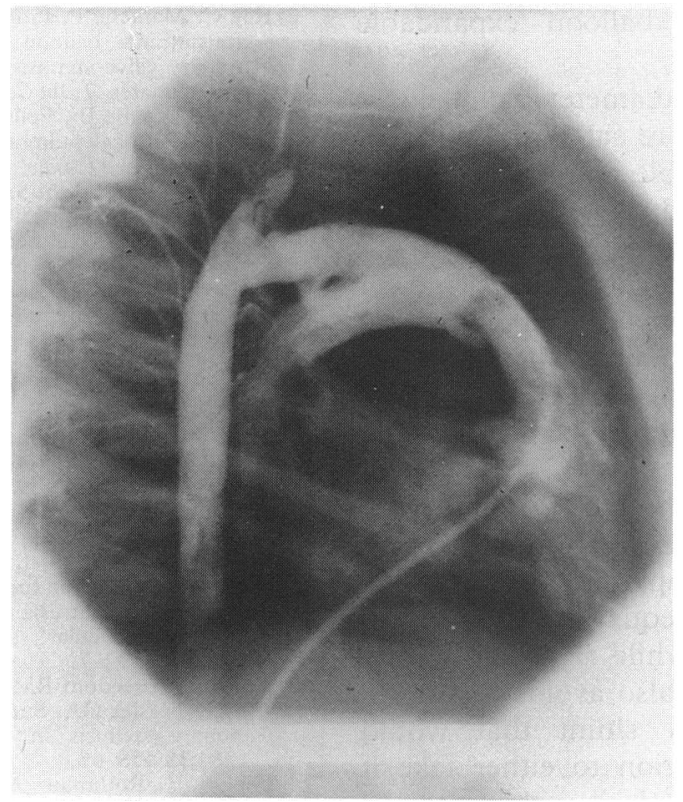

Both patients underwent cardiac catheterisation and balloon dilatation of the pulmonary valve within 24 hours of admission. Both had suprasystemic right ventricular pressures with right ventricle to femoral artery systolic pressure ratios of 1.51 and 1.84 . Right ventriculography in both showed a very hypertrophied ventricle with small cavity and a dysplastic doming pulmonary valve with an extremely small central jet (fig 1). On the lateral projection the tricuspid valves measured 11 and $10 \mathrm{~mm}$, and the pulmonary valves measured 6 and $5.3 \mathrm{~mm}$ in diameter. In each patient the valve was crossed with an 0.018 inch (William Cook) or 0.025 inch (Terumo Corporation) guide wire that was advanced to the distal left pulmonary artery or through the arterial duct into the descending aorta. The pulmonary valve was dilated serially with 6,8 , and $10 \mathrm{~mm}$ diameter balloons (Balt). After dilatation the peak systolic pulmonary valve gradient measured $26 \mathrm{~mm} \mathrm{Hg}$ in both patients with a right ventricle to femoral artery systolic pressure ratio of 0.72 and 0.7 . In view of the severe hypoplasia of the right ventricles both patients remained on $P G E_{2}$ infusions but became progressively more cyanosed with arterial $\mathrm{PO}_{2}$ of 28 and $24 \mathrm{~mm} \mathrm{Hg}$. Cross sectional echocardiography with colour flow mapping showed the arterial ducts to be considerably narrowed at their pulmonary ends. Therefore five and six days later both patients underwent arterial duct angioplasty. With a transvenous approach, a $4 \mathrm{~F}$ Gensini or multipurpose catheter was passed through the arterial duct and used to position an 0.018 inch or 0.032 inch exchange guide wire in the abdominal aorta. A $10 \mathrm{~mm}$ diameter $2 \mathrm{~cm}$ long balloon on a $5.5 \mathrm{~F}$ shaft was position 'd across the arterial duct and rapidly inflated with carbon dioxide gas and deflated, and then with dilute contrast. Aortic saturation increased from $78 \%$ to $86 \%$ and from $70 \%$ to $96 \%$ respectively and pulmonary artery pres- sure increased from $26 / 23$ to $52 / 20 \mathrm{~mm} \mathrm{Hg}$ and from $21 / 17$ to $46 / 21 \mathrm{~mm} \mathrm{Hg}$. Angiography in patient 2 showed a widely patent arterial duct after angioplasty (fig 2 ). A loud continuous murmur was easily heard in both patients who were no longer clinically cyanosed after treatment. In both patients the arterial duct was noted as becoming more restrictive on follow up echocardiograms and closed without clinical consequences after three months. Both have exhibited right ventricular growth on follow up echocardiography and neither has required further intervention during six months follow up.

\section{Discussion}

Neonates with critical pulmonary valve stenosis and intact ventricular septum are currently treated by balloon dilatation of the critically stenosed pulmonary valve. ${ }^{2-4}$ The degree of associated right ventricular hypoplasia is variable. ${ }^{1}$ The hypoplastic right ventricle has considerable potential for long-term growth after relief of the pulmonary valve stenosis, although its end diastolic volume and stroke volume decrease transiently after decompression. ${ }^{8}$ The right ventricle is unable to provide adequate pulmonary blood flow unassisted over this period and a systemic to pulmonary shunt, ${ }^{9}$ or prolonged administration of PG $E_{1}$ or $E_{2}$ is often required. ${ }^{4}$ Administration of $P G$ to maintain arterial duct patency over this period may avoid a surgical shunt and a further intervention to occlude it when it is no longer required. Unfortunately, $\mathrm{PGE}_{2}$ infusions produce sustained clinical improvement in only $60 \%$ to $88 \%$ of patients with cyanotic heart disease, ${ }^{6}$ and a surgical systemic to pulmonary shunt may be necessary. Arterial duct angioplasty provides an alternative to a surgical shunt in such patients.

We have recently shown that angioplasty of the arterial duct in neonates with severe left heart obstruction produces a widely patent duct and restoration of the systemic circulation where PG had failed. ${ }^{7}$ This report shows that angioplasty of the arterial duct is also effective in neonates with critical pulmonary stenosis and severe right ventricular hypoplasia who remain cyanosed after balloon dilatation of the pulmonary valve despite PG infusion. Arterial duct angioplasty resulted in an immediate increase in pulmonary blood flow. The ducts remained open for at least three months but showed evidence on Doppler echocardiography of gradual constriction. In these particular patients increasing forward flow through the growing right ventricle seemed to run parallel with the gradual narrowing of the duct thus avoiding overperfusion of the lungs. Formal duct closure was not required. In other types of cyanotic congenital heart disease such as pulmonary atresia where the pulmonary blood supply is entirely duct dependent, arterial duct angioplasty may not provide a secure long-term source of pulmonary blood supply. These patients require a surgical systemic to pulmonary shunt or possibly maintenance of 
duct patency with a balloon expandable endoluminal stent. ${ }^{10}$

We have used large diameter balloons for the angioplasty procedure safely despite previous reports of the friable nature of the duct after giving PG. Indeed, histological studies have shown that PG infusion results in an oedematous media with clear spaces and an increased number of breaks in the internal elastic lamina. ${ }^{11}$ It is possible that these PG induced alterations of the wall of the arterial duct render it more compliant and therefore safer to dilate.

In this particular subset of patients with critical pulmonary valve stenosis and severe right ventricular hypoplasia arterial duct angioplasty provides adequate sustained pulmonary blood supply while right ventricular growth is occurring. It also avoids a surgical systemic to pulmonary shunt that would require a further operation to either take it down surgically or occlude it with a detachable balloon when it is no longer required. ${ }^{12}$

1 Freed MD, Rosenthal A, Bernhard WF, Litwin SB, Nadas AS. Critical pulmonary stenosis with a diminutive right ventricle in neonates. Circulation 1973;48:875-81.
2 Rey C, Marache P, Francart C, Dupuis C. Percutaneous transluminal balloon valvuloplasty of congenital pulmonary valve stenosis with a special report on infants and neonates. $\mathcal{f} \mathrm{Am}$ Coll Cardiol 1988;11:815-20.

3 Zeevi B, Keane JF, Fellows KE, Lock JE. Balloon dilatation of critical pulmonary stenosis in the first week of life. $\mathcal{F}$ Am Coll Cardiol 1988;11:821-4.

4 Ladusans EJ, Qureshi SA, Parsons JM, Arab S, Baker EJ, Tynàn $M$. Balloon dilatation of critical stenosis of the pulmonary valve in neonates. Br Heart $\mathcal{f}$ 1990;63:362-7.

5 Graham TP, Bender HW, Atwood GF, Page DL, Sell GR. Increase in right ventricular volume following GR. Increase in right ventricular volume following
valvulotomy for pulmonary atresia or stenosis with intact ventricular septum. Circulation 1974;50(supp II):II-69-79.

6 Freed MD, Heymann MA, Lewis AB, Roehl SL, Kensey RC. Prostaglandin $E_{1}$ in infants with ductus arteriosusdependent congenital heart disease. Circulation 1981;64:899-905.

7 Walsh KP, Sreeram NS, Franks R, Arnold R. Balloon dilatation of the arterial duct in congenital heart disease. Lancet 1992;339:331-2.

8 Schmidt KG, Cloes J-I, Silverman NH. Changes of right ventricular size and function in neonates after valvotomy for pulmonary atresia or critical pulmonary stenosis and for pulmonary atresia or critical pulmonary stenosis and intact ventricular

9 Coles JG, Freedom RM, Olley PM, Coceani F, Williams WG, Trusler GA. Surgical management of critical pulmonary stenosis in the neonate. Ann Thorac Sur 1984;38:458-65.

10 Gibbs JL, Rothman MT, Rees MR, Parsons JM, Blackburn ME, Ruiz CE. Stenting of the arterial duct: a new approach to palliation for pulmonary atresia. $B r$ Heart $¥ 1992 ; 67: 240-5$.

11 Gittenberger-De Groot AC, Moulaert AJ, Harinck E Becker AE. Histopathology of the ductus arteriosus f after prostaglandin $\mathrm{E}_{1}$ administration in ductus depen

12 Dubois J, Cohen L, Brunelle F, Piechaud J, Kachaner J. Modified Blalock Taussig shunt anastomosis in a three month old child with pulmonary stenosis: embolization therapy. Pediatr Radiol 1991;21:198-9. 